\title{
Mechanistic Insights into First-row Late Transition Metal-catalysed (formal) Hydroamination of Unactivated Alkenes
}

\author{
Jérôme Hannedouche*
}

\begin{abstract}
This short review provides a mechanistic overview of the most relevant developments into the area of intra- and intermolecular hydroamination and formal hydroamination of unactivated alkenes (excluding allenes and 1,3-dienes) promoted by first-row late transition metal catalysts involving zinc, copper, iron and cobalt. The different activation strategies and mechanistic disparities encountered with these systems will be highlighted. The relevant literature from 2012 until early 2018 has been covered.
\end{abstract}

Keywords: Alkenes · Amines · First-row late transition metal $\cdot$ Hydroamination $\cdot$ Mechanistic studies

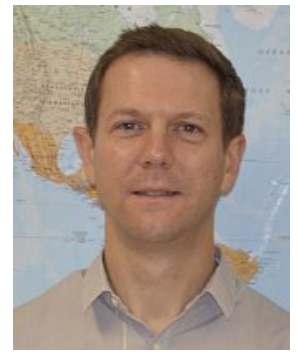

\section{Jérôme}

Hannedouche

received his $\mathrm{PhD}$ degree (2004) from the University of Warwick (UK) under the supervision of Prof. Martin Wills. After a 2-year postdoctoral stay at the Université Catholique de Louvain (Belgium) with Prof. Olivier Riant, he was appointed (2006) at the Institut de Chimie Moléculaire et des Matériaux d'Orsay (ICMMO) (Université ParisSud/Université Paris-Saclay, France) as a CNRS fellow researcher. His research interests lie in the development and mechanistic study of novel synthetic methodologies in asymmetric catalysis, mainly for $\mathrm{C}-\mathrm{N}$ bond formation via hydroamination reaction catalysed by rare-earth and firstrow late transition metal elements.
${ }^{*}$ Correspondence: Dr. J. Hannedouche

Institut de Chimie Moléculaire

et des Matériaux d'Orsay

UMR 8182, Université Paris-Sud,

Université Paris-Saclay

rue du doyen Georges Poitou, Orsay, F-91405, France

E-mail: jerome.hannedouche@u-psud.fr

\section{Introduction}

One of the most atom-efficient and conceptually simple methods to access valuable nitrogen-containing molecules from relatively inexpensive and ubiquitous starting reagents is the direct addition of $\mathrm{N}-\mathrm{H}$ bond of an amine across a $\mathrm{C}-\mathrm{C}$ double bond of an unactivated alkene, the so-called alkene hydroamination reaction. The main research activity of the past few decades in the field has focused on the development of Group 1-5 element- and noble metal-based catalysts to control the selectivities and broaden the scope of this atom-economic transformation. ${ }^{[1]}$ The rising trend for the use of earth-abundant, first-row late transition metals in catalysis has recently led to tremendous advances towards addressing some of the selectivity issues and extending the reaction scope. ${ }^{[1 \mathrm{e}]}$ These advances have been gained from the exploitation of established activation strategies but also from the emergence of novel formal hydroamination strategies that do not, strictly speaking, involve the direct addition of an amine onto an unactivated alkene. This short review will survey the most relevant developments in the area of (formal) hydroamination of unactivated alkenes (excluding allenes and 1,3-dienes) promoted by first-row late transition metal catalysts involving zinc, copper, iron and cobalt. Emphasis will be placed on catalytic systems for which the mechanism understanding has been gained through mechanistic studies to provide an overview of the different activation strategies and an update on mechanisms encountered with the systems described herein. It is beyond the scope of this review to cover all the on-going activity of the alkene hydroamination field and, in this context, the lit- erature coverage has been limited from 2012 until early 2018. Related developments in the addition of amines bearing electron-withdrawing substituents (such as amides, sulphonamides, carbamates...) on unactivated alkenes, will not be included as the addition of such electronically biased amines are today more appropriately referred to as alkene hydroamidation reactions. ${ }^{[1 \mathrm{~g}]}$

\section{Activation Mechanisms Overview}

Different strategies of activation of the reactants by the first-row late transition metal catalysts have been exploited to tackle the challenges associated with the alkene hydroamination reaction. These strategies can be gathered into two classes of mechanisms depending on whether the initial activation by the catalyst is on the alkene or the amine substrate. As schematically illustrated in Scheme 1 and according to the metallic system involved, the activation mechanism of the alkene by the catalyst may operate by either $\pi$-coordination of the alkene to the Lewis acidic metal centre or regiocontrolled hydrometalation or $\mathrm{H}$-atom transfer (HAT) mediated by an in situ-generated metal-hydride complex. The succeeding $\mathrm{C}-\mathrm{N}$ bond formation results from either nucleophilic attack of the amine on the electronically metalactivated alkene, umpolung electrophilic amination or radical coupling. In contrast, activation of the amine by the catalyst may proceed by deprotonation of the amine by a metal alkyl catalyst generating a reactive metal amido complex. Subsequentalkeneinsertion intothe metalamido $\sigma$-bond of this reactive complex leads to the $\mathrm{C}-\mathrm{N}$ bond formation. 


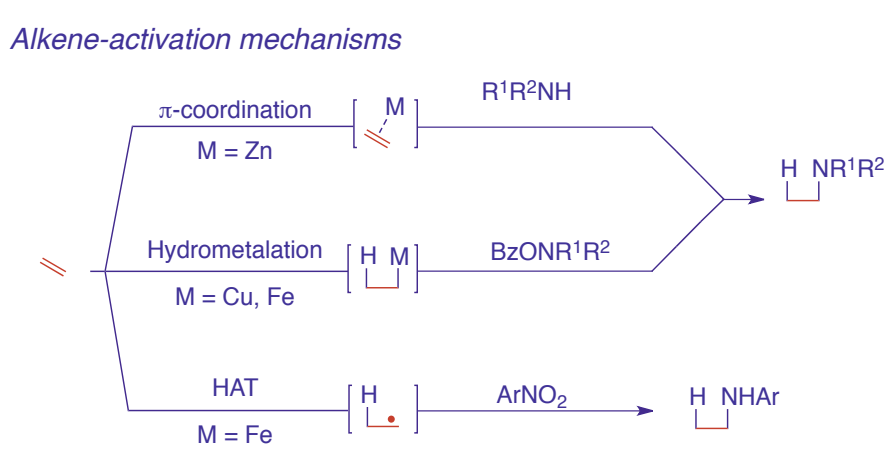

Scheme 1. Simplified overview of the alkene- and amine-activation mechanisms of zinc-, copper-, ironand cobalt-catalysed alkene hydroamination discussed herein.

Amine-activation mechanism

$$
\mathrm{R}^{1} \mathrm{R}^{2} \mathrm{NH}_{2} \underset{\mathrm{M}=\mathrm{Fe}, \mathrm{Co}, \mathrm{Cu}}{\stackrel{\text { Deprotonation }}{\longrightarrow}} \mathrm{M}-\mathrm{NR}^{1} \mathrm{R}^{2}
$$

\section{Alkene Activation Mechanisms}

\subsection{Alkene $\pi$-Coordination}

The olefin-activation mechanism by $\pi$-coordination is undoubtedly the most widely spread mechanism amongst the catalytic alkene hydroamination methodologies reported over the years and mediated by late transition metal elements. For example, it has been proposed from detailed mechanistic investigations that the monocationic rhodium system, $\left.\mathrm{Rh}(\mathrm{COD})_{2}\right] \mathrm{BF}_{4} /$ bis(diethylamino)xantphos ligand, which is among the most general and active late-transition metal-based systems reported so far for the alkene cyclohydroamination of primary and secondary amines, operates through a similar alkene-activation mode. ${ }^{[2]}$ From deep mechanistic and computational studies, an analogue olefin activation has also been suggested for the $[\operatorname{Ir}(\mathrm{COD}) \mathrm{Cl}]_{2}$-catalysed alkene hydroamination of aminoalkenes. ${ }^{[3]}$ In the burgeoning area of first-row late transition metals, this postulated activation pathway has been at the origin of the preliminary, and succeeding, catalyst developments for alkene hydroamination and related hydroamidation reactions with copper, ${ }^{[4]}$ iron $^{[5]}$ and zinc ${ }^{[6]}$ metal. In 2012, inspired by the elegant work of the Roesky group on the use of aminotroponiminate-ligated and ligand-free methyl zinc complexes for the cyclohydroamination of aminoalkenes, ${ }^{66]}$ Mandal and co-workers investigated the catalytic application of a well-defined methyl zinc complexes stabilised by a symmetrical $\mathrm{N}$-alkylsubstituted phenalenyl ligand $\mathbf{1}$ in alkene hydroamination (Scheme 2). ${ }^{[7]}$ During their investigations, they found that the catalytic activity was significantly enhanced in presence of the activator $\left[\mathrm{PhNMe}{ }_{2} \mathrm{H}\right]\left[\mathrm{B}\left(\mathrm{C}_{6} \mathrm{~F}_{5}\right)_{4}\right]$ as noticed previously by the Roesky group ${ }^{[6]}$ and that the $\mathrm{N}$-substituent of the ligand affects the reaction rate following the trend $\mathrm{Cy}(\mathbf{1 b})$ $\geq \operatorname{iPr}(\mathbf{1 a})>>\operatorname{Me}\left(\mathbf{1}\right.$ with $\left.\mathrm{R}^{4}=\mathrm{Me}\right)$. The more efficient catalytic systems $1 \mathbf{a}$ and 1b in presence of $\left[\mathrm{PhNMe}_{2} \mathrm{H}\right]\left[\mathrm{B}\left(\mathrm{C}_{6} \mathrm{~F}_{5}\right)_{4}\right]$ co-catalyst affords comparable catalytic activities to that of Roesky's [ $N$-isopropyl2-(isopropylamino)troponiminato] methylzinc catalyst for the intramolecular hydroamination of functionalised primary and secondary aminoalkenes into the corresponding 5- and 6-membered rings. To unravel the operating mechanistic cycle of the zinc-based hydroamination reaction, a combined experimental and computational study was conducted. As expected and as previously observed, in situ NMR experiment confirms the formation of a catalytically active cationic zinc species from the reaction of $\mathbf{1 a}$ and $\left[\mathrm{PhNMe}_{2} \mathrm{H}\right]$ $\left[\mathrm{B}\left(\mathrm{C}_{6} \mathrm{~F}_{5}\right)_{4}\right]$ by methyl abstraction from the boron-based Lewis activator. Kinetic studies underline a first-order and inverse de- pendence of the reaction rate with respect to catalyst concentration and aminoalkene concentration respectively and a significant primary kinetic isotope effect (KIE) for the cyclisation of both primary and secondary amines promoted by $\mathbf{1 a}$ and $\mathbf{1 b}$. DFT calculations done with catalyst $\mathbf{1 b}$, reveal that among the two most-accessible alkene- and amine-activation pathways, by respectively $\pi$-coordination and deprotonation, the mechanistic pathway involving alkene activation by the zinc cation is energetically the most favourable over the too energetically demanding amine activation pathway. Computational examination of the different ligation mode of the aminoalkene on the cationic zinc generated from $\mathbf{1 b}$ shows that the zinc species simultaneously binds to the alkene and the amine functionality is slightly more stable than the one solely bound to the alkene or the amine and points out that these species may be in rapid equilibrium. On the basis of these kinetic and computational features, the authors suggest that the reaction might proceed by first coordination of the alkene moiety to the electrophilic cationic zinc centre (generated from 1a and $\left.\left[\mathrm{PhNMe}_{2} \mathrm{H}\right]\left[\mathrm{B}\left(\mathrm{C}_{6} \mathrm{~F}_{5}\right)_{4}\right]\right)$ leading to the formation of species $\mathbf{A}$, which is in rapid equilibrium with $\mathbf{B}$ (and its analogue monoligated by the amine functionality) suggested to be the catalyst resting state (Scheme 2). Then, the coordinated alkene undergoes nucleophilic nitrogen attack by the tethered amine moiety to generate the ammonium alkylzinc adduct $\mathbf{C}$ and subsequent intramolecular rate-limiting proton
Scheme 2. Cationic zinc-catalysed exo-cyclohydroamination of primary and secondary amines tethered to terminal alkenes and its proposed mechanism operating by $\pi$-coordination of the alkene $(L=$ phenalenyl ligand).

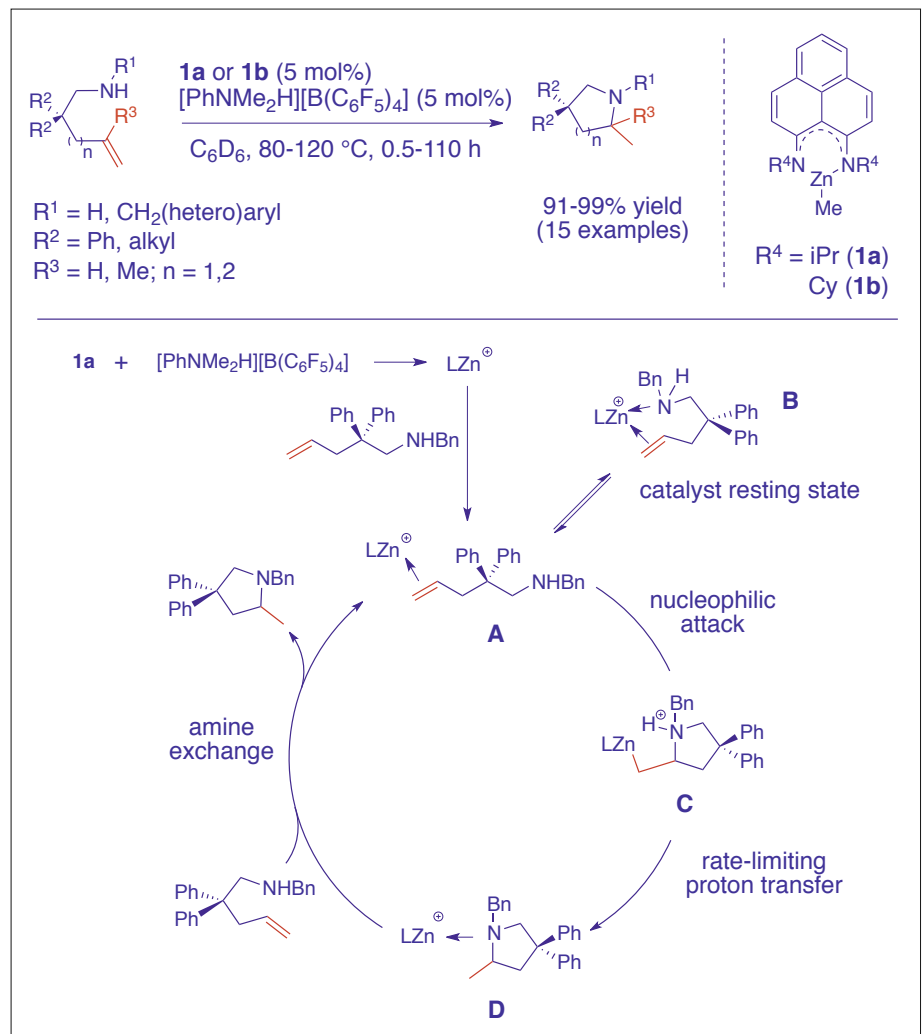


transfer from the ammonium functionality onto the $\mathrm{Zn}-\mathrm{C}$ unit provides the product-ligated zinc complex $\mathbf{D}$ by cleavage of the $\mathrm{Zn}-\mathrm{C} \sigma$-bond. Displacement of the product by the incoming aminoalkene regenerates the catalytically competent species $\mathbf{A}$ and liberates the cyclised hydroamination product. DFT calculations further indicate that the higher stability of the cationic zinc complex derived from $\mathbf{1 b}$, evaluated by the value of its HOMO-LUMO energy gap, accounts for the higher activity of this complex among the assessed series of $\mathrm{N}$-alkylsubstituted phenalenyl-based zinc complexes.

Early in 2017, a copper-based methodology proceeding through a similar alkene-activation strategy was disclosed by the group of Monnier and Taillefer. ${ }^{[8 a]}$ This methodology that uses copper(II) triflate as catalyst is the first report of copper-catalysed hydroamination of terminal allenes and cyclic secondary amines (or aniline), both partners bearing functional groups. This procedure provides selectively the corresponding linear $(E)$-allylamines as sole hydroamination products under mild reaction conditions, but with large excess of amine. A collaborative experimental and theoretical mechanistic study with the groups of Ciofini and Grimaud elegantly identified a cationic copper(I) species as the catalytically competent active species and rationalised the observed regioand stereoselectivity for the linear $(E)$ allylamine product. ${ }^{[8 \mathrm{~b}, \mathrm{c}]}$ This study allows the extension of the methodology to other classes of allene-type compounds.

\subsection{Alkene Hydrometalation}

In 2013, the Hirano/Miura's ${ }^{[9]}$ and Buchwald's ${ }^{[10]}$ groups independently reported a mechanistically novel approach for the $\mathrm{C}-\mathrm{N}$ bond formation from arylalkenes and hydroxylamine esters as amine sources, elegantly exploiting the well-developed phosphine-based copper-hydride chemistry[11] and the electrophilic character ${ }^{[12]}$ of hydroxylamine esters. These original reports, that are tremendous breakthoughs in the field of formal hydroamination, emphasise that the combination of a copper(I) or (II) source and a chiral biphosphine ligand in the presence of a reducing silane agent are particularly efficient catalytic systems for the enantio- and regioselective intermolecular formal hydroamination of arylalkene derivatives and $O$-benzoylhydroxylamines via an umpolung electrophilic amination strategy. ${ }^{[13]}$ The Buchwald system $((R)$ DTBM-SEGPHOS.Cu(OAc) $)_{2}(2 \mathrm{~mol} \%) /$ $\mathrm{HSiMe}(\mathrm{OEt})_{2}$ ) offers a broader substrate scope than the Hirano/Miura system $((S, S)$ Me-Duphos (or $(R, R)-\mathrm{Ph}-\mathrm{BPE}) \cdot \mathrm{CuCl}(10$ $\mathrm{mol} \%) / \mathrm{LiO}^{t} \mathrm{Bu} /$ diethoxymethylsilane) and is nowadays the most exploited sys- tem. The former is indeed well-suited for the conversion of a variety of functionalised styrenes, cis/trans- $\beta$-substituted and $\beta, \beta$-disubstituted arylarenes, vinylsilanes, alkenyl 1,8-diaminonaphthyl boronates and 1,1-dialkyl-substituted alkenes into the corresponding chiral branched amines, $\alpha$-amino silanes, $\alpha$-amino boronic acid derivatives and $\beta$-chiral amines in good to excellent yields and with high enantioinduction (Scheme 3). ${ }^{[10,14]}$ Thanks to the use of electrophilic nitrogen partners bearing a 4-(dimethylamino)benzoate moiety, this DTBM-SEGPHOS-CuH-based process was successfully extended to the preparation of chiral secondary amines and the conversion of highly challenging and rarely explored internal olefins. ${ }^{[15]}$ It was observed that the introduction of the more electron-rich 4-(dimethylamino)benzoate group on the amine transfer agent instead of the previously employed benzoate group was crucial to reach high hydroamination yields in these transformations.

In-depth experimental and computational investigations, ${ }^{[16]}$ conducted on the hydroamination of styrenes and $O$-benzoyl$N, N$-dialkyl-hydroxylamine promoted by the Buchwald system and a simplified version of the reported racemic Hirano/ Miura system ((1,2-bis(diphenylphosphino)benzene $\left.\cdot \mathrm{Cu}(\mathrm{OAc})_{2} / \mathrm{LiOtBu} / \mathrm{Me}_{3} \mathrm{SiH}\right)$ respectively, favour the mechanistic picture depicted in Scheme 4. Initial treatment of the biphosphine(L*)/copper(II) acetate with an hydrosilane results, after reduction and transmetalation, in the formation of catalytically competent monomeric $\mathrm{L} * \mathrm{Cu}(\mathrm{I}) \mathrm{H}$ (supported by the linear relationship ee $\left.e_{\text {prod }}=\mathrm{f}\left(\mathrm{ee}_{\text {ligand }}\right)\right)$, which is in equilibrium with its dimer or higher-order species (or aggregates), as suggested by the observation of an apparent fractional order dependence of the rate on copper concentration. ${ }^{[17]}$ Subsequent regioselective 2,1-migratory insertion of the styrene olefin into the $\mathrm{L} * \mathrm{Cu}(\mathrm{I}) \mathrm{H} \sigma$-bond through a four-centre planar transition state gives an alkyl copper(I) species E (Scheme 4). Linear free energy relationships between the Hammet electronic parameters of $p$-substituted styrene derivatives and the observed enantiomeric excesses, and deuterium-labelling experiments suggest that the hydrocupration step is enantio-determining and irreversible. Subsequent electrophilic amination of the ensuing alkyl copper(I) species $\mathbf{E}$ by the amination reagent occurs by cleavage of the amine $\mathrm{N}-\mathrm{O}$ bond via intramolecular $\mathrm{S}_{\mathrm{N}} 2$ displacement, that produces species $\mathbf{F}$, followed by facile and stereoretentive reductive elimination. This step leads to the $\mathrm{C}-\mathrm{N}$ bond formation and product release, and forms $\mathrm{L} * \mathrm{CuOCOAr}$ which should be the catalyst resting state as revealed by NMR and MS studies. The active $\mathrm{L} * \mathrm{Cu}(\mathrm{I}) \mathrm{H}$ catalyst is regenerated by transmetalation between the copper carboxylate and the silane reagent. The linear Hammet correlation between the reaction rate with the electronic parameters of $p$-substituted amine electrophiles indicates that more electron-rich amine electrophiles increase the reaction rate. This observation, coupled to the absence of influence of the $p$-substitution of the styrene on the rate, the zero-order dependence of the rate on styrene and amine concentration and the first-order rate dependence on silane concentration are consistent with the catalyst regeneration being the rate-limiting step of the catalytic cycle.

From these mechanistic insights, the enhanced efficiency of more-electron rich esters on the amine transfer agent

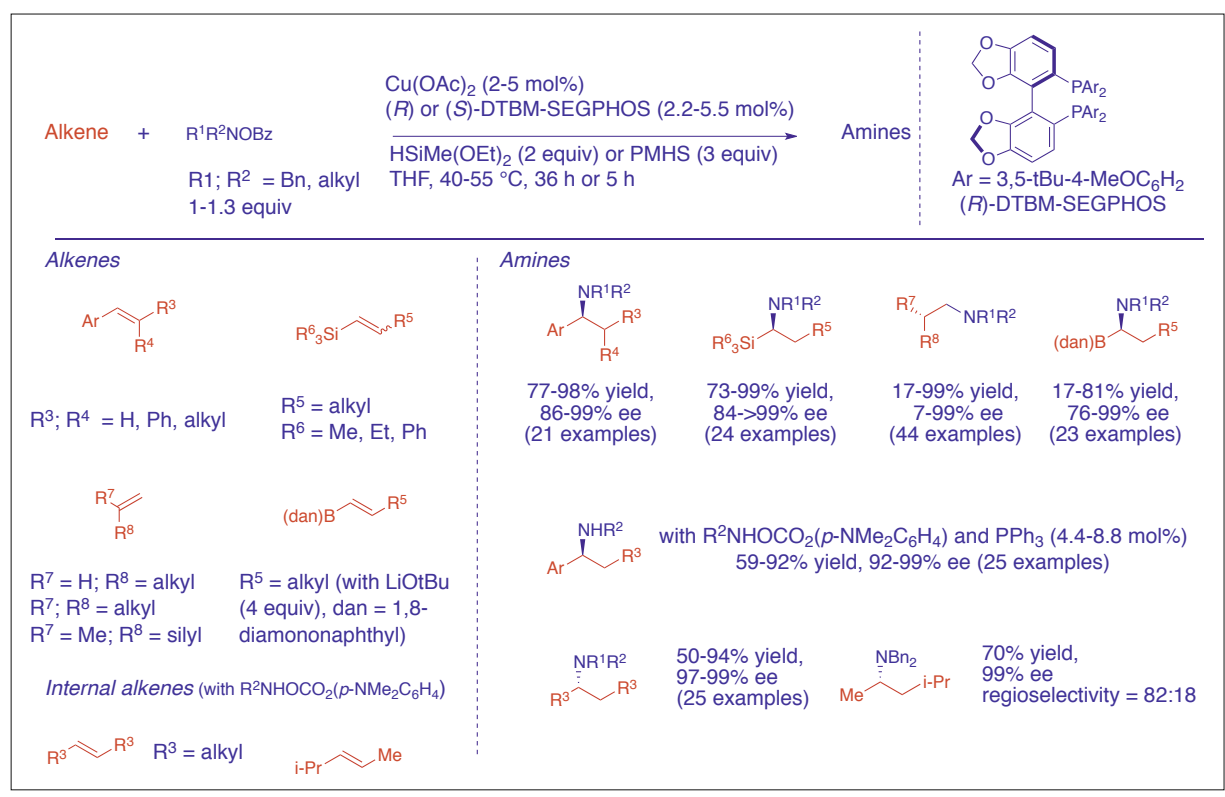

Scheme 3. Regio- and enantioselective (R)-DTBM-SEGPHOS-CuH-catalysed formal hydroamination of alkene derivatives and $\mathrm{N}, \mathrm{N}$-dialkyl-O-benzoyl hydroxylamines. 


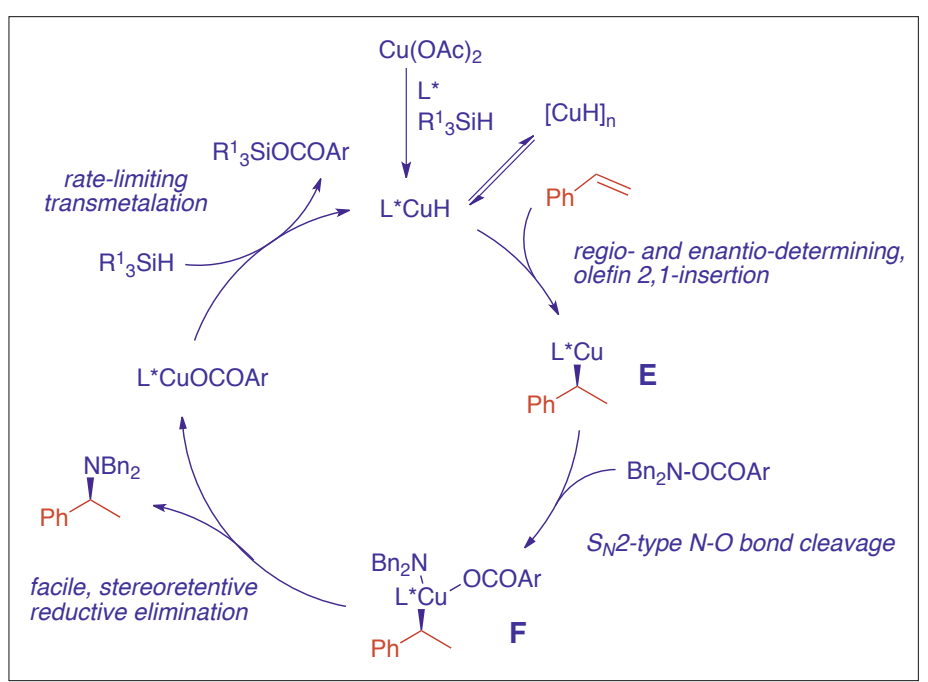

Scheme 4. Proposed mechanism for $(R)$-DTBM-SEGPHOS-CuH-catalysed formal hydroamination of alkene derivatives and $\mathrm{N}, \mathrm{N}$-dialkyl-O-benzoyl hydroxylamines proceeding by alkene hydrometalation $\left(\mathrm{L}^{*}\right.$ $=(R)$-DTBM-SEGPHOS). may result from a better regeneration of the active copper hydride species and a reduced non-productive degradation of the electrophilic amine by the catalyst as supported by DFT calculations. ${ }^{[16 b]}$ The observed Markovnikov and anti-Markovnikov selectivity for arylalkenes (and vinylsilanes) and linear alkenes may be rationalised by electronic stabilisation of the alkylcopper intermediate by the adjacent aryl or silyl group and generation of a less sterically hindered alkylcopper intermediate during the enantio-determining step. Computational studies examining the through-bond and through-space interactions between the $\mathrm{CuH}$ catalyst bearing various biphosphine ligands and aliphatic alkenes reveal that the enhanced reactivity observed with the bulky biphosphine ligand DTBM-SEGPHOS results essentially from greater dispersion interactions between the tert-butyl groups on the ligand and the alkyl substituent of the olefin, stabilising the hydrocupration transition state. ${ }^{[16 c]}$ Moreover, DFT calculations on the enantio-determining hydrocupration step of trans-butene mediated by $(R)$ DTBM-SEGPHOS-CuH shows that the high alkene enantiofacial discrimination comes from the spatial organisation of the tert-butylsubstituted aryl groups of the ligand during this step. ${ }^{[15 b]}$ From this better mechanistic understanding, further optimisation studies have been conducted on the structure of the turnover-limiting step components (silane, amine transfer agent) and led, with the aid of additives $\left(\mathrm{PPh}_{3}\right.$, $t \mathrm{BuOH})$, to significant improvement in terms of efficiency, scope and practicality. ${ }^{[16 a, 18,19]}$

A similar electrophilic amination approach based on iron was reported by the group of Yang for the regioselective Markovnikov hydroamination of arylalkenes and hydroxylamine esters using the catalytic system $\mathrm{FeCl}_{2} / 2$,6diiminopyrdine ligand in the presence of cyclopentylmagnesium bromide (4 equiv) as reducing agent. ${ }^{[20]}$ In contrast to the copper system, this system is not suitable for the hydroamination of $\alpha$ - and $\beta$-methylstyrenes, $p-\mathrm{Cl}$ and $p$ - $\mathrm{CF}_{3}$-styrene and aliphatic terminal alkenes. From mechanistic studies, and similarly to the CuH-methodology, a regioselective hydrometalation of styrene from a $\mathrm{FeH}$ species (generated from $\mathrm{FeCl}_{2}$ and Grignard reagent) is proposed as the key step, followed by electrophilic amination of the subsequent iron alkyl complex.

\subsection{H-Atom Transfer (HAT)}

In 2015, the group of Baran reported an iron-based methodology for formal alkene hydroamination that operates via a different mechanism than the alkene-activation by $\pi$-coordination or hydrometalation described above. ${ }^{[21]}$ Exploiting some literature background ${ }^{[22]}$ and their own expertise on $\mathrm{Fe}(\mathrm{III})-\mathrm{H}$ promoted $\mathrm{H}$-atom transfer (HAT) processes for radical mediated $\mathrm{C}-\mathrm{C}$ bond formation from alkene substrates, ${ }^{[23]}$ the group discloses a convenient iron-hydride-mediated procedure for $\mathrm{C}-\mathrm{N}$ bond formation from the reaction of nitro(hetero)arenes and mono- and polysubstituted alkenes leading to the synthesis of (hetero)aryl secondary amines substituted by a secondary or tertiary alkyl group. ${ }^{[24]}$ Using the ligand-free pre-catalyst $\mathrm{Fe}(\mathrm{acac})_{3}(30 \mathrm{~mol} \%)$ and an excess of $\mathrm{PhSiH}_{3}$ (2-3 equiv) under the optimal reaction conditions described in Scheme 5 , a prominent range of hindered (hetero) aryl secondary amines was prepared in low to good isolated yields and with exclusive Markovnikov selectivity. This airand moisture-compatible procedure has an impressive broad functional group tolerance including amide, amine, alcohol, thioether, ketone, halide, nitrile, triflate, boronic acid and this provides a great opportunity for further derivatisations in an orthogonal manner to the classical $\mathrm{C}-\mathrm{N}$ bond formation methodologies. However, this method, that requires an excess of olefin, is limited to nitro(hetero)arenes as nitroalkanes deliver no or low yields of hydroamination product and is not compatible with $\alpha$-substituted styrenes, 2-nitropyridines, nitroimidazoles and nitrophenyl bearing ortho-esters or free thiol or alcohol. From literature precedents ${ }^{[25]}$ and some control experiments, the authors propose that the reaction proceeds via the mechanism displayed in Scheme 5. This mechanism accounts for the formation of the desired hydroamination product and the main by-products, the amino(hetero) arenes (from reduction of the nitro(hetero)arene) and the $\mathrm{N}, \mathrm{O}$-alkylated products H. The initial reaction of $\mathrm{Fe}(\mathrm{acac})_{3}$ and $\mathrm{PhSiH}_{3}$ in EtOH generates in situ $\left[\mathrm{Fe}^{\mathrm{n}}\right]-\mathrm{H}$ species. ${ }^{[26,27]}$ This hydride species will further promote the formal single-electron reduction of both the nitro(hetero)arene into a nitroso(hetero)arene and the substituted alkene into the corresponding alkyl radical intermediate by regioselective HAT. Both reductions will liberate $\left[\mathrm{Fe}^{\mathrm{n}-1}\right]$ species. The nitroso species (ArNO) could be further reduced by $\left[\mathrm{Fe}^{\mathrm{n}}\right]-\mathrm{H}$ species into the arylamine, which was isolated as side-product. Succeeding radical attack of either one or two equivalent(s) of alkyl radical on the nitroso functionality would form the oxygen-centred radical $\mathbf{G}$ and $\mathrm{N}, \mathrm{O}$-dialkyl compound $\mathbf{H}$ respectively. Single-electron reduction of $\mathbf{G}$ by $\left[\mathrm{Fe}^{\mathrm{n}-1}\right]$ species will give the corresponding hydroxylamine anion intermediate, which after solvolysis and second single-electron reduction, will provide the hydroamination product and regenerate the active $\left[\mathrm{Fe}^{\mathrm{n}}\right]^{+}$ species. Alternatively, the hydroxylamine intermediate formed after solvolysis could also originate from a proton transfer process between $\mathbf{G}$ and a $\left[\mathrm{Fe}^{\mathrm{n}}\right]-\mathrm{H}$ species as suggested by the authors. The double alkylation compound $\mathbf{H}$, otherwise isolated as a byproduct, is converted into the formal hydroamination product by $\mathrm{Zn} / \mathrm{HCl}$ treatment. Control experiments point out that iron is involved in the activation of both reaction partners and that nitroso(hetero)arenes and hydroxylamines, and not amino(hetero)arenes, are part of the productive pathway of $\mathrm{C}-\mathrm{N}$ bond formation. Some improvements to this iron-hydride based methodology in terms of reaction temperature and catalyst loading were subsequently disclosed using isopropox$y$ (phenyl)silane and an amine-bis(phenolate)iron(III) complex respectively.[28]

\section{Amine Activation Mechanism}

The preferred elements of the periodic table for encountering mechanisms proceeding by amine activation via initial deprotonation are unquestionably the Group I-IV (and to a lesser extent Group V) elements involving strongly basic cat- 
alysts. Early in 2014 and in the quest to develop an undisclosed iron-based alkene hydroamination methodology for electronically unbiased primary amines, the group of Hannedouche considered using this amine activation mode, generally reserved to Group I-V catalysts, to design efficient iron-based hydroamination catalysts. ${ }^{[29]}$ Encouraged by previous reports, ${ }^{[30]}$ the group speculated that structurally defined low coordinate $\beta$-diketiminatoiron(II) alkyl complexes could have an adequate reactivity to primarily activate the unprotected primary amines tethered to alkenes and subsequently deliver the hydroamination product. Indeed, optimisation studies have highlighted that the well-defined four-coordinate $\beta$-diketiminatoiron(II) alkyl complex 2-Fe was efficient as catalyst for the selective exo-cyclisation of primary amines tethered to alkenes, giving the corresponding 5- and 6-membered ring compounds in good to excellent yields at $90^{\circ} \mathrm{C}$ (Scheme $6)$. The presence of a catalytic amount of cyclopentylamine as a non-bulky non cyclisable primary amine additive allows to enhance the hydroamination selectivity (over the oxidative amination) from $83 \%$ (without additive) to $96 \%$ but at the expense of the reaction rate. This methodology is, up to now, restricted to gem-disubstituted aminoalkenes as Thorpe-Ingold-free substrates do not cyclise under these reaction conditions. The kinetic dependence of the cyclohydroamination reaction was determined to be first-order on the catalyst concentration and inverse-order upon the aminoalkene and cyclopentylamine concentration. A KIE $\left(\mathrm{k}_{\mathrm{H}} / \mathrm{k}_{\mathrm{D}}\right)$ value of $3\left(90^{\circ} \mathrm{C}\right)$ was measured upon analysis of the reaction of an $\mathrm{N}$-proteo-amine versus an $\mathrm{N}$-deuteroamine. The observed kinetic isotope effect on the cyclisation reactivity suggests that a $\mathrm{N}-\mathrm{H}$ bond breaking is involved in the rate-limiting step of the catalytic cycle. Stoichiometric reaction of $\mathbf{2 - F e}$ and 2,2-diphenylpent-4-en-1-amine that leads to the formation of iron amido complex $\mathbf{I}$, structurally characterised as a centrosymmetric amido-bridged dimer $[\mathbf{I}]_{2}$ in the solid state, endorses the activation of the amine moiety by the basic iron catalyst. Additionally, the formation of insertive products from the isolated reactivity of this dimer confirms the viability of migratory insertion of the tethered alkene into the $\mathrm{Fe}-\mathrm{N} \sigma$-bond of the complex. It was noticed a similar catalytic efficiency between complexes $\mathbf{2 - F e}$ and $[\mathbf{I}]_{2}$, also reflecting the involvement of the latter in the catalytic cycle. On the basis of these kinetic studies and the observed reactivities of isolated iron-amido dimer $[\mathbf{I}]_{2}$, a stepwise $\sigma$-insertive mechanism featuring a rate-determining aminolysis step was proposed as operating mechanism (Scheme 6a). This insertive type mechanism has been previously suggested

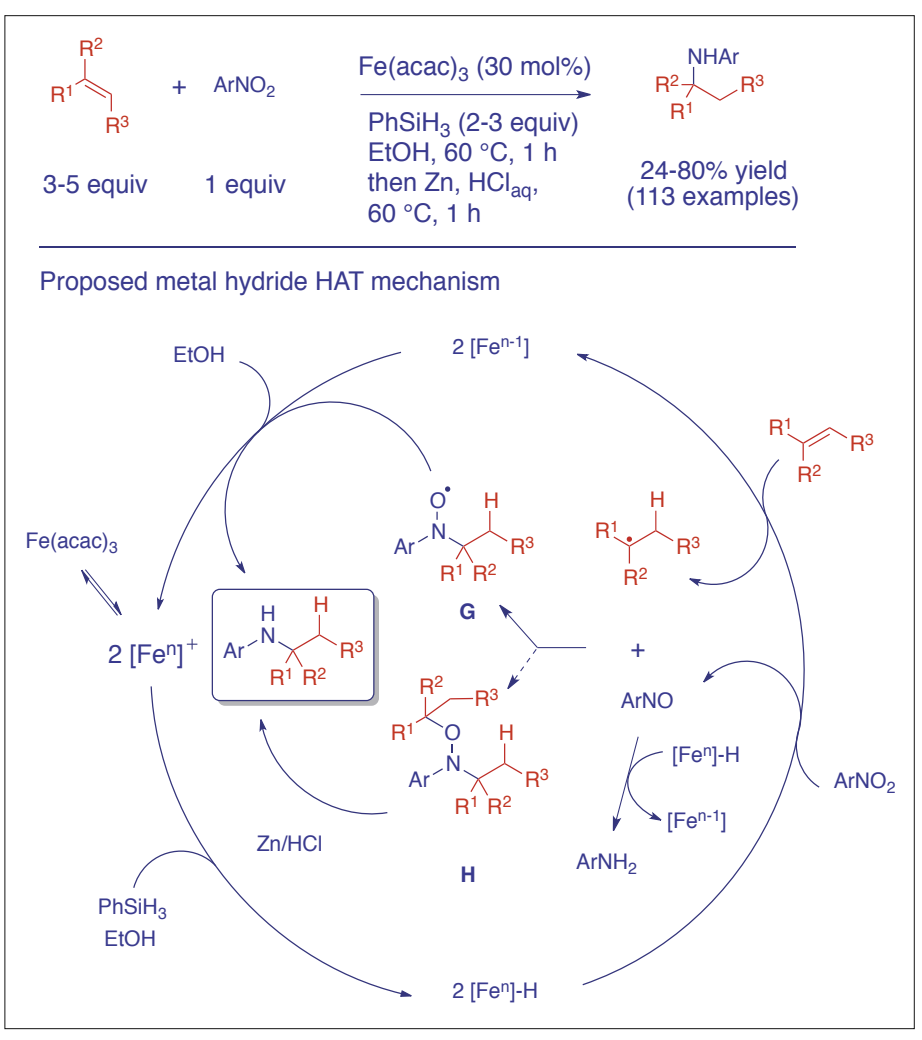

Scheme 5. Iron-promoted formal hydroamination of nitro(hetero)arenes and (poly)substituted alkenes and its proposed metal-hydride $\mathrm{H}$-atom transfer (HAT) mechanism.

as preferred mechanistic pathway for some alkaline and rare earth element-catalysed alkene hydroamination reactions. ${ }^{[31]}$ Initial $\sigma$-bond metathesis between the coordinatively unsaturated iron complex 2-Fe leads to the formation of monomeric complex $\mathbf{I}$, which is in rapid equilibrium with its dimer $[\mathbf{I}]_{2}$. Then 1,2-migratory insertion of the pendant alkene into the $\mathrm{Fe}-\mathrm{N} \sigma$-bond of $\mathbf{I}$ provides the insertive complex $\mathbf{J}$ featuring a $\mathrm{Fe}-\mathrm{C} \sigma$-bond which subsequently undergoes turnover-limiting aminolysis with either the aminoalkene or cyclopentylamine to deliver the competent catalytic species I and the cyclopentylamido complex $\mathbf{K}$ respectively with liberation of the hydroamination product. The similar catalytic efficiency of $\mathbf{K}$, independently prepared, is consistent with an equilibrated process between $\mathbf{I}$ and $\mathbf{K}$. The extended reaction time in presence of this additive may be attributed to the presence of this equilibrium process. The beneficial effect of the amine additive on the reaction selectivity, that results from the competitive pathways for rate-determining aminolysis and $\beta$-hydride elimination of $\mathbf{J}$, may arise from the involvement of the additive in the rate-limiting step.

In 2009, the group of Sawamura reported an efficient copper-based catalytic system $(\mathrm{Cu}(\mathrm{O} t$-Bu $) / 4,5$-bis(diphenylphosphino)9,9-dimethylxanthene (Xantphos)) for the exo-cyclohydroamination of primary and secondary amines tethered to terminal alkenes affording the corresponding pyrrolidines and piperidines in excellent yields (79-99\%). Although no mechanistic evidence has been gained, this system is proposed to go through a similar stepwise $\sigma$-insertive mechanism. [32]

Early this year, Hannedouche and co-workers in collaboration with the group of Ujaque and Lledos have explored the reactivity of the cobalt analogue 2-Co of iron complex 2-Fe in alkene hydroamination and disclosed that such a well-defined low coordinate $\beta$-diketiminatocobalt(II) alkyl complex also displays unique catalytic abilities to promote the selective exo-cyclohydroamination of primary alkenylamines and represents the first cobalt-mediated hydroamination of unprotected primary amines. ${ }^{[33,34]}$ In contrast to the iron complex, 2-Co requires the introduction of a phenyl ring at the terminal position of the substrate alkene unit to avoid isomerisation of the alkene as the main reactive pathway. Under this condition, a range of gem-disubstituted pyrrolidines and piperidines bearing functionalised aryl rings has been prepared and isolated in satisfactory yields (Scheme 6). The reaction mechanism has been scrutinised by stoichiometric, kinetics and deuterium-labelling experiments and detailed computational studies. On the basis of these investigations and in contrast to the iron complex, an original stepwise non-insertive mechanism was put forward (Scheme 6b). This mechanism features, after $\sigma$-bond metathesis between 2-Co and the aminoalkene and coordination of a second substrate molecule, a rate-determining nucleophilic attack of the amido functionality of the resulting monomeric cobalt(II) amidoalkene-aminoalkene adduct intermediate $\mathbf{L}$ to the non coordinated tethered alkene leads to the formation of zwitteri- 

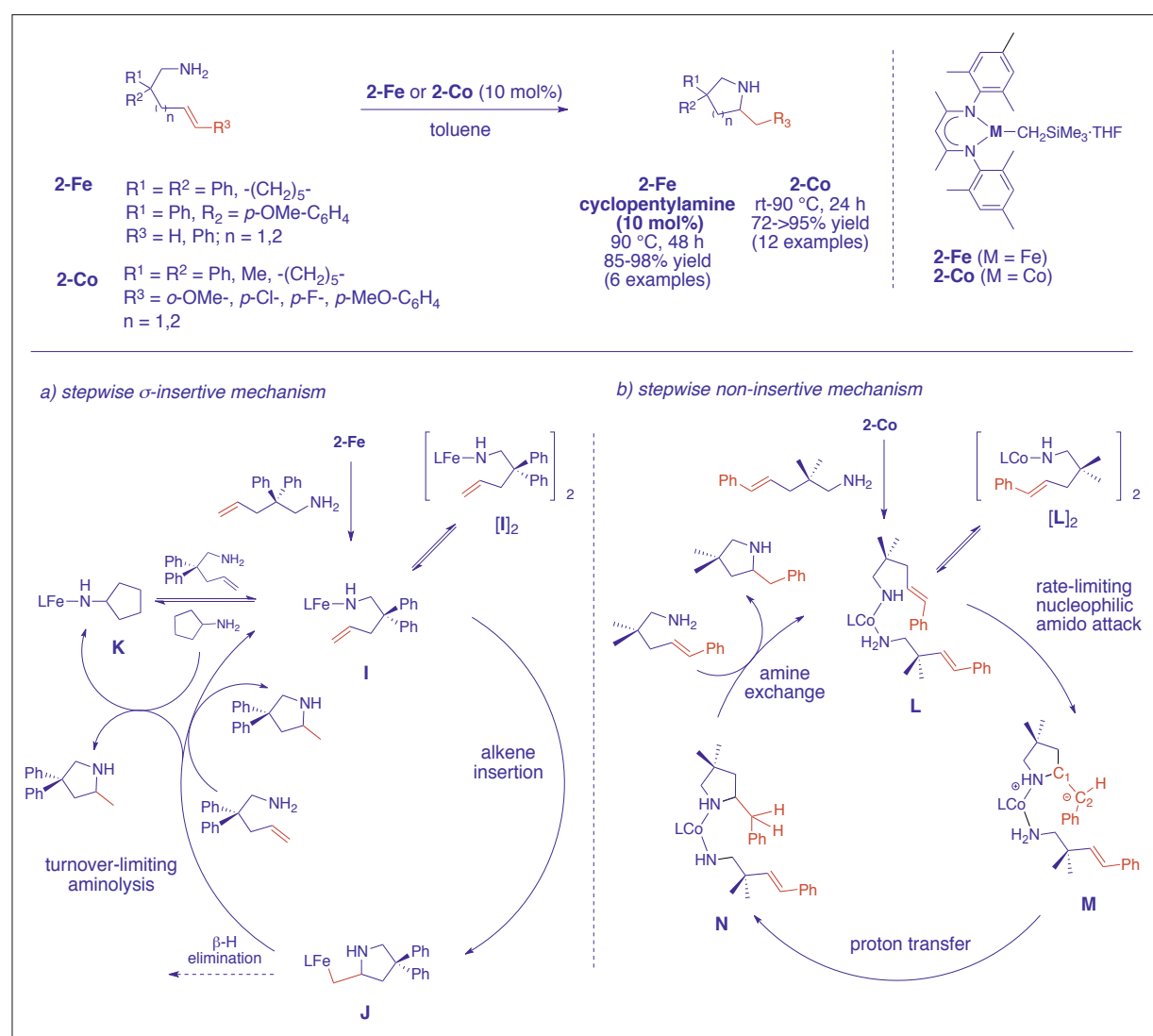

Scheme 6. $\beta$-Diketiminatoiron(II) and -cobalt(II)-catalysed exo-cyclohydroamination of primary amines tethered to alkenes and their distinct associated mechanisms operating by amine deprotonation ( $L=\beta$-diketiminato ligand).

onic species M. Species $\mathbf{L}$ is proposed as the catalytically competent active species in rapid equilibrium with its centrosymmetric amido-bridged dimer $[\mathbf{L}]_{2}$ which was isolated and characterised by X-ray diffraction analysis. The rate-limiting step is associated subsequently to a rapid proton transfer from the amino moiety of the coordinated aminoalkene to the methylene anion $\mathrm{C}_{2}$ of $\mathbf{M}$ providing neutral intermediate $\mathbf{N}$. The active species $\mathbf{L}$ is regenerated by displacement of the cyclised product by another substrate molecule. Detailed computational DFT studies endorse the non-insertive character of the mechanistic proposal as no direct interaction between the Co centre and $\mathrm{C}_{2}$ was observed. They also show that this non-insertive mechanism prevails energetically over alternative mechanistic pathways including the classical alkene-activation by $\pi$-coordination and two previously reported amine-activation by deprotonation, namely the stepwise $\sigma$-insertive and the concerted non-insertive pathways. The latter concerted pathway was proposed as an alternative operating mechanism to the stepwise $\sigma$-insertive mechanism for some alkaline, rare earthand Group IV element-catalysed alkene hydroaminations. ${ }^{[35]}$ This mechanism goes by concomitant $\mathrm{C}-\mathrm{N} / \mathrm{C}-\mathrm{H}$ bond formation at a metal amido-/amino-alkene species via a multi-centre transition state. The observation of $\mathrm{C}-\mathrm{N}$ bond formation in a reactivity study of isolated dimer $[\mathbf{L}]_{2}$ without the assistance of an additional amine militates against such a concerted process. The proposed stepwise non-insertive mechanism for this cobalt-catalysed hydroamination methodology is in agreement with the empirical second-order rate law $\left(\mathrm{v}=\mathrm{k}[\text { Co catalyst }]^{1}[\text { aminoalkene }]^{1}\right)$, no KIE observation, the syn-addition of N-D bond across the $\mathrm{C}-\mathrm{C}$ double bond, and the activation parameters determined experimentally. Calculations have shown that for $\mathbf{M}$ the rapid proton transfer is faster than the $\mathrm{C}_{1}-\mathrm{C}_{2}$ bond rotation and accounts for the syn-stereochemistry of the cyclisation.

\section{Conclusion}

This short review offers an outline of the mechanistic studies conducted on the most relevant and recent developments in the nascent field of first-row late transition metal-catalysed hydroamination of unactivated alkenes. This underlines the richness and diversity of implemented approaches to unravel, through alkene- or amine-activation, some of the remaining challenges of the transformation in terms of scope, regio- chemo- and enantioselectivity. It is manifest that the emergence of the well-established copper-hydride chemistry and the iron-hydride mediated radical chemistry, via a highly regiocontrolled (and enantio- controlled) hydrometalation and $\mathrm{H}$-atom transfer process of the alkene have elegantly enriched the portfolio of alkene-activation mechanisms leading to some outstanding successes and milestones in the field. However, the overall atom- and -step efficiency of these formal hydroamination strategies deviate from the original concept of hydroamination. Research studies that have been conducted to meet the criteria of a truly hydroamination transformation using more classical alkene $\pi$-coordination or amine deprotonation as activation strategies need to be emphasised and reinforced. Undoubtedly, the mechanistic understandings gained through these deep investigations will inspire the next development and rational design of base metal catalysts with enhanced, or alternative, one- or two-electron reactivity and selectivity in olefin hydroamination but also in other alkene hydrofunctionalisation reactions.

\section{Acknowledgements}

Financial support from the CNRS and Univ Paris Sud are gratefully acknowledged.

Received: July 2, 2018

[1] a) T. E. Muller, K. C. Hultzsch, M. Yus, F. Foubelo, M. Tada, Chem. Rev. 2008, 108, 3795; b) K. D. Hesp, M. Stradiotto, ChemCatChem 2010, 2, 1192; c) J. Hannedouche, E. Schulz, Chem. Eur. J. 2013, 19, 4972; d) E. Bernoud, C. Lepori, M. Mellah, E. Schulz, J. Hannedouche, Catal. Sci. Technol. 2015, 5, 2017; e) C. Lepori, J. Hannedouche, Synthesis 2017, 49, 1158; f) V. Rodriguez-Ruiz, R. Carlino, S. Bezzenine-Lafollée, R. Gil, D. Prim, E. Schulz, J. Hannedouche, Dalton Trans. 2015, 44, 12029; g) L. Huang; M. Arndt, K. Gooßen, H. Heydt, L. J. Gooßen, Chem. Rev. 2015, 115, 2596.

[2] L. D. Julian, J. F. Hartwig, J. Am. Chem. Soc. 2010, 132, 13813.

[3] K. D. Hesp, S. Tobisch, M. Stradiotto, J. Am. Chem. Soc. 2010, 132, 413

[4] a) J. G. Taylor, N. Whittall, K. K. Hii, Org. Lett. 2006, 3561; b) C. Michon, F. Medina, F. Capet, P. Roussel, F. Agbossou-Niedercorn, Adv. Synth. Catal. 2010, 35, 3293.

[5] a) K. Komeyama, T. Morimoto, K. Takaki, Angew. Chem. Int. Ed. 2006, 45, 2938; b) J. Michaux, V. Terrasson, S. Marque, J. Wehbe, D. Prim, J. -M. Campagne, Eur. J. Org. Chem. 2007, 2601; c) X. Cheng, Y. Xia, H. Wei, B. Xu, C. Zhang, Y. Li, G. Qian, X. Zhang, K. Li, W. Li, Eur. J. Org. Chem. 2008, 1929; d) M. S. Jung, W. S. Kim, Y. H. Shin, H. J. Jin, Y. S. Kim, E. J. Kang, Org. Lett. 2012, 14, 6262.

[6] a) A. Zulys, M. Dochnahl, D. Hollmann, K. Löhnwitz, J.-S. Herrmann, P. W. Roesky, S. Blechert, Angew. Chem. Int. Ed. 2005, 44, 7794; b) M. Dochnahl, J.-W. Pissarek, S. Blechert, K. Löhnwitz, P. W. Roesky, Chem. Commun. 2006, 3405; c) K. Löhnwitz, M. J. Molski, A. Lühl, P. W. Roesky, M. Dochnahl, S. Blechert, Eur. J. Inorg. Chem. 2009, 1369; d) J.-W. Pissarek, D. Schlesiger, P. W. Roesky, S. Blechert, Adv. Synth. Catal. 2009, 351, 2081; e) M. Dochnahl, K. Löhnwitz, A. Lühl, J.-W. Pissarek, M. Biyikal, P. W. Roesky, S. Blechert, Organometallics 2010 , 29, 2637; f) J. Jenter, A. Lühl, P. W. Roesky, S. Blechert, J. Organomet. Chem. 2011, 696, 406. 
[7] a) A. Mukherjee, T. K. Sen, P. Kr. Ghorai, P. P. Samuel, C. Schulzke, S. K. Mandal, Chem. Eur J. 2012, 18, 10530; b) A. Mukherjee, T. K. Sen, P. Kr. Ghorai, S. K. Mandal, Organometallics 2013, 32, 7213 .

[8] a) R. Blieck, J. Bahri, M. Taillefer, F. Monnier, Org. Lett. 2016, 18, 1482; b) L. A. Perego, R. Blieck, A. Groué, F. Monnier, M. Taillefer, I. Ciofini, L. Grimaud, ACS Catal. 2017, 7, 4253 c) L. A. Perego, R. Blieck, J. Michel, I. Ciofini, L. Grimaud, M. Taillefer, F. Monnier, $A d v$. Synth. Catal. 2017, 359, 4388.

[9] Y. Miki, K. Hirano, T. Satoh, M. Miura, Angew. Chem. Int. Ed. 2013, 52, 10830.

[10] S. Zhu, N. Niljianskul, S. L. Buchwald, J. Am. Chem. Soc. 2013, 135, 15746.

[11] a) A. J. Jordan, G. Lalic, J. P. Sadighi, Chem. Rev. 2016, 116, 8318; b) C. Deutsch, N. Krause, B. H. Lipshutz, Chem. Rev. 2008, 108, 2916.

[12] M. Corpet, C. Gosmini, Synlett 2014, 46, 2258.

[13] For a review on copper-catalysed formal hydroamination using hydroxylamine esters: M. T. Pirnot, Y.-M. Wang, S. L. Buchwald, Angew. Chem. Int. Ed. 2016, 55, 48.

[14] a) N. Niljianskul, S. Zhu, S. L. Buchwald Angew. Chem. Int. Ed. 2015, 54, 1638; b) D. Nishikawa, K. Hirano, M. Miura, J. Am Chem. Soc. 2015, 137, 15620; c) S. Zhu, S. L. Buchwald, J. Am. Chem. Soc. 2014, 136, 15913

[15] a) D. Niu, S. L. Buchwald, J. Am. Chem. Soc. 2015, 137, 9716; b) Y. Yang, S.-L. Shi, D. Niu, P. Liu, S. L. Buchwald, Science 2015, 349, 62 c) Y. Xi, T. W. Butcher, J.; Zhang, J. F. Hartwig, Angew. Chem. Int. Ed. 2016, 55, 776.

[16] a) J. Bandar, M. T. Pirnot, S. L. Buchwald, J. Am. Chem. Soc. 2015, 137, 14812; b) S. Tobisch, Chem. Eur. J. 2016, 22, 8290; c) G. Lu, R. Y. Liu, Y. Yang, C. Fang, D. S. Lambrecht, S. L. Buchwald, P. Liu, J. Am. Chem. Soc. 2017 $139,16548$.

[17] J.-T. Issenhuth, F.-P. Notter, S. Dagorne, A. Dedieu, S. Bellemin-Laponnaz, Eur. J. Inorg. Chem. 2010, 529.

[18] a) H. Wang, J. C. Yang, S. L. Buchwald, J. Am. Chem. Soc. 2017, 139, 8428; b) S. Ichikawa, S.
Zhu, S. L. Buchwald, Angew. Chem. Int. Ed. 2018, 57,8714

[19] For incorporation of this CuH-based methodology in tandem/relay catalysis processes: a) S.-L. Shi; S. L. Buchwald, Nat. Chem. 2015, 7, 38; b) S.-L. Shi, Z. L. Wong, S. L. Buchwald, Nature 2016, 532, 353; c) S. Zhu, N. Niljianskul, S. L. Buchwald, Nat. Chem. 2016, 8, 144.

[20] C. B. Huehls, A. Lin, J. Yang, Org. Lett. 2014, 16,3620 .

[21] J. Gui, C. M. Pan, Y. Jin, T. Qin, J. C. Lo, B. J. Lee, S. H. Spergel, M. E. Mertzman, W. J. Pitts, T. E. La Cruz, M. A. Schmidt, N. Darvatkar, S. Natarajan, P. S. Baran, Science 2015, 348, 886.

[22] a) E. G. Janzen, Acc. Chem Res. 1971, 4, 31; b) K. Kato, T. Mukaiyama, Chem. Lett. 1992, 21, 1137; c) E. K. Leggans, T. J. Barker, K. K. Duncan, D. L. Boger, Org. Lett. 2012, 14, 1428.

[23] J. C. Lo, Y. Yabe, P. S. Baran, J. Am. Chem. Soc. 2014, 136, 1304; b) J. C. Lo, J. Gui, Y. Yabe, C.-M. Pan, P. S. Baran, Nature 2014, 516, 343.

[24] For a historical background and a full presentation of this work: M. Villa, A. J. von Wangelin, Angew. Chem. Int. Ed. 2015, 54, 11906.

[25] For a full and background account on iron-mediated radical hydrofunctionalisation of alkenes: $\mathrm{S}$. W. M Crossley, C. Obradors, R. M. Martinez, R. A. Shenvi, Chem. Rev. 2016, 116, 8912.

[26] H. Nakazawa, M. Itazaki, Top. Organomet. Chem. 2011, 33, 27.

[27] For recent investigations on the actual species formed: J. C. Lo, D. Kim, C.-M. Pan, J. T. Edwards, Y. Yabe, J. Gui, T. Qin, S. Gutiérrez, J. Giacoboni, M. W. Smith, P. L. Holland, P. S. Baran, J. Am. Chem. Soc. 2017, 139, 2484

[28] a) C. Obradors, R. M. Martinez, R. A. Shenvi, J. Am. Chem. Soc. 2016, 138, 4962; b) K. Zhu, M. P. Shaver, S. P. Thomas, Chem. Asian J. 2016, 11, 977; c) K. Zhu, M. P. Shaver, S. P. Thomas, Chem. Sci. 2016, 7, 3031 .

[29] E. Bernoud, P. Oulié, R. Guillot, M. Mellah, J. Hannedouche, Angew. Chem. Int. Ed. 2014, 53, 4930.

[30] a) T. J. J. Sciarone, A. Meetsma, B. Hessen, Inorg. Chim. Acta 2006, 359, 1815; b) J. Vela,
S. Vaddadi, T. R. Cundari, J. M. Smith, E. A. Gregory, R. J. Lachicotte, C. J. Flaschenriem, P. L. Holland, Organometallics 2004, 23, 5226; c) J. Vela, J. M. Smith, R. J. Lachicotte, P. L. Holland, Chem. Commun. 2002, 2886; d) T. J. J. Sciarone, A. Meetsma, B. Hesssen, J. H. Teuben, Chem. Commun. 2002, 1580; e) J. M. Smith, R. J. Lachicotte, P. L. Holland, Organometallics 2002, 21, 4808; f) H. Andres, E. Bominaar, J. M. Smith, N. A. Eckert, P. L. Holland, E. Münck, J. Am. Chem. Soc. 2002, $124,3012$.

[31] For theoretical mechanistic investigations: a) S Tobisch, Chem. Eur. J. 2011, 17, 14974; b) S. Tobisch, Dalton Trans. 2012, 41, 9182.

[32] a) H. Ohmiya, T. Moriya, M. Sawamura, Org. Lett. 2009, 11, 2145; b) H. Ohmiya, M. Yoshida, M. Sawamura, Synlett 2010, 2136.

[33] C. Lepori, P. Gómez-Orellana, A. Ouharzoune, R. Guillot, A. Lledós, G. Ujaque, J. Hannedouche, ACS Catal. 2018, 8, 4446.

[34] For a cobalt-catalysed intramolecular C-N bond formation by formal hydroamidation reaction of protected amines bearing electron-withdrawing groups that proceeds by alkene-activation: $\mathrm{H}$. Shigehisa, N. Koseki, N. Shimizu, M. Fujisawa, M. Niitsu, K. Hiroya, J. Am. Chem. Soc. 2014, 136, 13534.

[35] For a few recent examples: a) J. F. Dunne, D. B. Fulton, A. Ellern, A. D. Sadow, J. Am. Chem. Soc. 2010, 132, 17680; b) K. Manna, M. L. Kruse, A. D. Sadow, ACS Catal. 2011, 1, 1637; c) B. Liu, T. Roisnel, J.-F. Carpentier, Y. Sarazin, Angew. Chem. Int. Ed. 2012, 51, 4943 d) D. C. Leitch, R. H. Platel, L. L. Schafer, J. Am. Chem. Soc. 2011, 133, 15453; e) K. Manna, W. C. Everett, G. Schoendorff, A. Ellern, T. L. Windus, A. D. Sadow, J. Am. Chem. Soc. 2013 135,7235 . 